IZA DP No. 6234

Concept and Unintended Consequences of Weather Index Insurance: The Case of Mexico

Alan Fuchs

Hendrik Wolff

December 2011 


\title{
Concept and Unintended Consequences of Weather Index Insurance: The Case of Mexico
}

\author{
Alan Fuchs \\ University of California at Berkeley \\ Hendrik Wolff \\ University of Washington \\ and IZA
}

\section{Discussion Paper No. 6234}

December 2011

IZA

P.O. Box 7240

53072 Bonn

Germany

Phone: +49-228-3894-0

Fax: +49-228-3894-180

E-mail: iza@iza.org

Any opinions expressed here are those of the author(s) and not those of IZA. Research published in this series may include views on policy, but the institute itself takes no institutional policy positions.

The Institute for the Study of Labor (IZA) in Bonn is a local and virtual international research center and a place of communication between science, politics and business. IZA is an independent nonprofit organization supported by Deutsche Post Foundation. The center is associated with the University of Bonn and offers a stimulating research environment through its international network, workshops and conferences, data service, project support, research visits and doctoral program. IZA engages in (i) original and internationally competitive research in all fields of labor economics, (ii) development of policy concepts, and (iii) dissemination of research results and concepts to the interested public.

IZA Discussion Papers often represent preliminary work and are circulated to encourage discussion. Citation of such a paper should account for its provisional character. A revised version may be available directly from the author. 
IZA Discussion Paper No. 6234

December 2011

\title{
ABSTRACT
}

\section{Concept and Unintended Consequences of Weather Index Insurance: The Case of Mexico*}

\begin{abstract}
Recently, Weather Index Insurance (WII) has received considerable attention as a tool to insure farmers against weather related risks, particularly in developing countries. Donor organizations, local governments, insurance companies, development economists as well as agricultural economists are discussing the costs and benefits of WII. While the literature on WII has mainly focused on many cases in Africa and Asia, in this article we analyze the WII program in Mexico, which is one of the largest WII programs worldwide. In this context we discuss potentially important spill-over effects on related markets which so far have not been considered in the academic literature. First, we argue that WII creates disincentives to invest in other non-insured crops leading to potential overspecialization and monoculture. Secondly, WII generates disincentives to invest in irrigation systems because farmers are insured only as long as production takes place on non-irrigated land. Third, in case of catastrophic events food prices can potentially inflate with indemnity payments at the expense of the uninsured poor. We also suggest that in Mexico the thresholds of the weather index be (continuously) re-calibrated in order to adjust for the development of drought resistant seeds. Finally, the index could relatively easily be extended to account for precipitation variances. We argue that these factors and spillover effects should be accounted for in cost benefit analysis of WII.
\end{abstract}

JEL Classification: $\quad$ Q11, Q14, O13, G22

Keywords: $\quad$ Weather Index Insurance, policy evaluation, Mexico

Corresponding author:

Hendrik Wolff

University of Washington

Department of Economics

349 Savery Hall, Box 353330

Seattle, WA 98195-353330

USA

E-mail: hgwolff@u.washington.edu

\footnotetext{
We thank the National Science Foundation for financial support. Alan Fuchs also thanks CONACYT/UC-MEXUS and Ford Foundation through Colegio de México/PRECESAM for financial support.
} 


\section{Background}

The productivity of agriculture is highly influenced by the conditions of the natural environment. In particular, changes in climatic and weather conditions impact farmers' yields, and in developing countries - where a high percentage of the gross domestic product is generated by agricultural income-unfavorable conditions can severely affect the overall well-being of an entire region. Traditionally, farmers have developed several coping mechanisms to mitigate the potential negative impacts of their exposure to natural risks, namely by investments in:

- crop diversification (planting multiple crops with different vulnerabilities to weather events),

- $\quad$ irrigation systems (to decrease the farmers dependence on precipitation)

- the generation of off-farm incomes

- formal and informal banking systems (either by accumulating savings or access to credit markets).

Today, despite the existence of these risk mitigating mechanisms, in developing countries a large portion of weather shocks' negative effects are still not entirely absorbed, which in some cases can lead to humanitarian catastrophes such as famines or civil wars over access to important resources (Barnett and Mahul 2007, Alderman and Haque 2008). More generally, the lack of tools to insure sectors against weather shocks has led to an underinvestment in the agricultural sector (Rosenzweig and Binswanger 1993, Morduch 1995). 
Historically, governments have used disaster relief funds to respond quickly and stabilize areas affected by floods or droughts. However, the volatility of disaster funds over time-and the associated strains on other governmental budgets, e.g., education or security, from which the resources are taken-pose difficulties. Furthermore, disaster relief is an "ex-post" strategy only. In recent years efforts increased at designing "exante” strategies. In theory, under the assumption of risk aversion, an optimally designed WII facilitates overcoming credit constraints, mitigates chronic underinvestment, increases productivity and could potentially relieve poor farmers from poverty traps as discussed in Barnett, Barrett and Skees (2008).

\section{Weather Index Insurance Literature and Challenges}

Although weather index insurance contracts are currently considered to be an effective tool for the agricultural sector in developing countries (i.e. Sakurai and Reardon 1997; Skees 1999 and 2000, Skees and Ayurzana 2002, Barnett and Mahul 2007, Barnett, Barrett and Skees 2008) the first successful implementation has been realized in the U.S. in 1997: after the deregulation of the energy sector, energy providers increasingly insured themselves against mild winters to compensate for potential loss of revenue due to the decreased use of energy for heating (Cao Li and Wei 2003). Since then, stakeholders in the sectors of tourism, agriculture, travel and event organization have engaged in the trading of weather derivatives which became a 40 billion dollar business for the Chicago Mercantile Exchange alone in 2006 (Ginocchio 2008).

The basic concept of WII is simple: if a certain measured weather index (i.e. precipitation) is above (flood) or below (drought) a pre-defined threshold, then the 
insurance pays indemnity payments to the insurance holder (farmer). While we will discuss the challenges of this mechanism in more detail below, the perceived advantages of WII are that it circumvents both moral hazard and adverse selection, which are problems in traditional insurance schemes that are based on actual losses of harvest. Furthermore, it is often argued (Barnett and Mahul 2007, Barnett, Barrett and Skees 2008) that WII is cost effective because no harvest damage assessment has to be made.

Regarding the economics and feasibility of the insurance program, important recent insights have been gained in the case of India, Malawi and China. The main empirical problem is the take-up rate by farmers purchasing WII, ranging (depending on the study) in 2004 from 4-5\% as analyzed by Giné, Townsend and Vickery (2008) in India, to rates of about $27 \%$ for the same sample of Indian farmers in 2006 as analyzed by Cole et al (2008). These studies and a series of additional papers (Giné and Yang 2009, Cai et al. 2009) analyze the determinants of participation of WII and find: the higher the correlation between the weather index and the yield (basis risk), the higher the take-up rate. Furthermore, take-up increases with household wealth and with less restrictive credit constraints. These results are consistent with the predictions of simple neoclassical models. The above studies however also point towards important social-psychological and peer-effect related determinants for take-up, namely trust in the insurance program, participation in village networks, and familiarity with the insurance vendors. These variables are consistently correlated with the take-up decision. Furthermore Giné, Townsend and Vickery (2008) performed experiments with farmers to measure their degree of risk aversion. The authors found-now contrary to the theoretical predictions 
from the neoclassical model—that risk averse farmers are less (not more) likely to participate in WII, which may reflect their uncertainty about the WII program itself. In an already widely cited paper, Giné and Yang (2009) study the interaction between access to credit and access to WII, which is important given that one argument in favor of WII is that it helps farmers overcome credit constraints. Their findings, in randomized field experiments in Malawi, were that farmers who were offered credit were less likely to adopt the credit if simultaneously the farmer was also offered a WII (compared to the control group of farmers that were offered credit only). Giné and Yang interpret this result with limited liability of the loan contract: farmers already are implicitly insured by the limited liability inherent in the loan contract, so that bundling a loan with formal insurance (for which an insurance premium is charged) is effectively an increase in the interest rate on the loan (Giné and Yang 2009, p. 2). Another potential interpretation that Giné and Yang offer is of psychological nature, in the sense that by offering both credit and WII, farmers are reminded of the risk of defaulting the credit and hence decide to accept neither. Finally, an additional interpretation (not described in Giné and Yang) is that for the 'average' Malawi groundnut and maize farmer, the simultaneous offer of both credit and insurance is simply too complicated to understand. Hence farmers may decide to accept neither contract due to their uncertainty with the details of the various policies and the interaction of the policies in case of a default. Suggestive evidence for this hypothesis is supported by the fact that the adoption of both offers increases with education, income and wealth. ${ }^{1}$ 
Based on these experiences a debate has emerged whether WII is an efficient tool for developing countries and whether WII is self-sustainable. Due to the low take-up ratessome donor organizations are now more hesitant to further invest resources into WII. For example, after a workshop on WII at the Headquarters of the Bill and Melinda Gates Foundation in Seattle, the Foundation decided not to further support and engage in weather index insurance programs (Wolff 2010).

However, the design of the Mexican insurance program differs from other WII programs in several important ways. Therefore, we think it is worth looking at in greater detail in order to have a better understanding of the potential role, costs and benefits and effectiveness of different WII design options. Below, we will examine some of the main problem areas of WII. Barnett and Mahul (2007) and Barnett, Barrett and Skees (2008) contributed papers which conceptually discuss the main challenges, which can be categorized into (i) basis risk (ii) low data quality, and (iii) low willingness to pay. We further discuss the problem of diversification, technology inertia, and other aggregate equilibrium effects.

\section{Weather Index Insurance in Mexico}

Agricultural Background

Mexico's WII is designed to insure against droughts in non-irrigated agricultural production. It covers four crops: maize, barley, beans and sorghum on a total of 1.9 million hectares. The insurance mainly targets maize: of the total 1.9 million hectares insured, $81 \%$ (1.5 million hectares) is devoted to maize. In Mexico, maize is the most important crop, and its relative dominance is even higher in non-irrigated agriculture: 
$90 \%$ of all maize is grown on rain-fed land and the remaining $10 \%$ of all maize is grown on irrigated land. ${ }^{2}$

Eighty percent of all agricultural catastrophes in Mexico are caused by drought. This situation is exacerbated in El Niño phenomenon years. Federal and State Governments spent around a third of a billion U.S. dollars in disaster relief due to agricultural catastrophes between 1995 and 2003 (Ministry of Agriculture 2009). Moreover, access to private agricultural production insurance in Mexico is insufficient since land fragmentation (more than $60 \%$ of farmers own less than 5 hectares), large administrative costs and systemic risk discourage private insurers. Due to the lack of private insurers and the high budgeting uncertainty of disaster relief funds, the Mexican Government, through the Ministry of Agriculture, introduced the rainfall index insurance in 2003. The insurance's objective is to efficiently support small-scale producers-defined as owning no more than 20 hectares - in the case of adverse droughts.

\section{Regional Enrollment versus Private Take-Up}

While in 2003 the insurance was only available in five counties, in 2008 the insurance covered over 656 counties with a total of 1.9 million hectares. In particular, every year since 2003 state level officials suggest to their federal counterpart the area to be insured (number of hectares and counties considered) within the first three months of the year and before the beginning of the season. The federal government pays $70 \%$ of the cost of the insurance premiums and state governments cover the remaining 30\%. However, for counties that have high poverty levels (defined by the National Population Council), costs are split $90 \%$ to $10 \%$ between federal and state governments, respectively. In Mexico, 
“Agroasemex” a governmental agency formed in 2001, provides exclusive coverage. An important aspect of the WII in Mexico is that although it provides production insurance for small-scale farmers, Agroasemex essentially insures the federal government budgets. In other words, it serves as a budget risk management tool since it allows annual budget planning minimizing catastrophic ex-post expenditure due to droughts. Agroasemex itself reinsures their risk with the U.S. re-insurance company Partner RE, hence spreading the covariate risk on an international level. On the international level reinsurers can regard a country's risk as an idiosyncratic risk if the reinsurer itself invests in multiple countries. Importantly, in Mexico individual producers do not pay premiums to obtain coverage under the WII. Instead, WII is jointly contracted by federal and state governments that provide resources from their annual budgets to purchase insurance premiums. The automatically insured farmers get informed about their coverage status through state officials. ${ }^{3}$ However, whether this information channel is effective and farmers are truly aware of this insurance coverage is an open question. In order to evaluate the information channels, the Ministry of Agriculture hence requires that the program be externally evaluated. In particular, during the latest external evaluation of 2009 it was demanded that a subset of randomly selected farmers be surveyed to determine their awareness of and willingness to pay for the insurance. According to the Ministry of Agriculture (2009) this external evaluation proved that (i) almost $100 \%$ of the farmers know about the existence of the insurance, and (ii) over $80 \%$ of the farmers reveal a positive willingness to pay for the premium (in order to obtain the insurance in case the government would not provide it for free). However, it is important to point out that this study—although 
classified as external to the interests of the government—was contracted by the Mexican government and may not satisfy strict scientific criteria. In particular, the result that there exists a positive willingness to pay among Mexican farmers is in stark contrast to the results found by Giné, Townsend and Vickery (2008), Cole et. al. (2008) in India, Giné and Yang (2009) in Malawi 2008, and Cai et al. (2009) in China. Given the importance and academic interest of this issue, this problem should be analyzed further.

\section{Data Quality}

The Mexican WII program takes advantage of existing and publicly available weather data. Although there are more than five thousand weather stations in the country, Agroasemex only uses a subset since few of these stations attain international standards and have more than 25 years of daily weather information. The 25 year requirement was introduced because it was regarded important to obtain a long enough time series to statistically predict the rain-yield correlation pattern.

Basis risk Modeling and the problem of non-moving thresholds

"Basis risk" is often viewed as the most significant problem with WII design (basis risk describes how well the index is correlated with crop yields). To model the relationship between weather conditions and crop yields, the Mexican "Agricultural Insurance Simulation Model" was developed. This model is important as it is used to determine the critical threshold index values below which indemnity payments are triggered (Agroseamex 2006). The model consists of a system of equations representing the cropsoil-weather relationship, taking into account the specifics of each agronomic climate region. As a result, the growing season is separated into three phases (seeding, flowering, 
harvest). Different thresholds are established for each of these three phases, for each crop and for each agro-climatic zone. The agro-climatic zones are referred to as Agro-Climatic Zone of Homogeneous Response (ACZHR). Indemnity payments are provided if rainfall is below the pre-established threshold, as measured in millimeters by weather stations in the ACZHR. As an example, we look at the case of a zone in the state of Guanajuato in figure 1 corresponding to the rainfall of the year 2005. Agroasemex offers the following contract for insuring maize in the county "Apaseo el Alto". The first period, also known as the sowing period, runs from May 15 to July 5; the second period, or flowering period, from July 6 to August 20; and the third, or harvesting period, from August 21 to October 31. The minimum amount of cumulative rain above which Agroasemex does not provide indemnity payments (known as the trigger threshold) equals 43, 80 and 60 millimeters for the first, second and third period, respectively. As can be seen from figure 1, there were no indemnity payments in Apaseo el Alto, since cumulative rainfall was higher in each of the three periods than the minimum thresholds. Figure 2 shows the rainfall pattern for the county Leon in 2005. Indemnity payments were provided in 2005 for maize production in Leon since cumulative rainfall was lower than the sowing period minimum threshold. Given the importance of the thresholds for WII, in our opinion it is problematic that these thresholds stay constant over time. In Mexico, since the start of the program in 2003, the defined thresholds were not re-adjusted although currently a substantial amount of research has been devoted to the development of drought resistant corn and maize types (Ribaut et al. 2009). Non-moving thresholds can inhibit important incentives to invest in 
research and development of drought-resistant seeds. Hence we suggest a model recalibration and the consideration of appropriately moving thresholds over time.

In addition, we consider that not only the minimum amount of cumulative rain in each period is important, but also its variance within that period. In other words, attaining the minimum amount of cumulative rainfall in one or two days (potential flood) has very different consequences on the growing conditions of maize compared to the same amount of cumulative rainfall dispersed over a larger number of days. Therefore, we suggest an additional index which counts the number of days with a positively measured rainfall minimum. If a minimum number of days of rainfall is not reached, then the indemnity payment is triggered.

Risk of non-diversification: monoculture and inertia in technology

In Mexico 22\% of all rain-fed maize production is currently insured and it is intended that the program will be scaled up to the entire nation. In rolling out the program over larger regions, however, incentives to the farmers are lacking to diversify (i.e. into crops which are not insured) and so we see the risk of crop overspecialization. Maize monoculture has potential negative effects on the environment and long term sustainability (Berzsenyi 2000).

More generally, a strong WII creates disincentives to invest in other important agricultural technologies. For example WII may decrease efforts to invest in the development of irrigation systems because farmers are insured only if crops are planted on rain-fed land. Irrigation, however, is widely accepted to be the main technology responsible for crop yield increases in arid areas, especially in developing countries. 
Similarly, due to the nationwide rollout of the WII the structure of the rural work-force can be affected by reducing off-farm income, which prior to the WII program was one of the major risk coping mechanisms in Mexico.

Aggregate equilibrium effects of disaster prevention

The Mexican WII program was initially designed by the government for budget planning purposes to produce an ex-ante disaster prevention strategy which has no volatility in budget size. There is considerable work on WII as a tool to prevent disasters and famines (Barnett, Barrett and Skees 2008, Chantarat et al. 2007). For a WII program with such large coverage as in Mexico, however, the problem is that under food shortages sudden indemnity payments can lead to rapid food price increases. This may be particularly true in rural areas, which are not well integrated into larger markets and where maize is a necessity with very low own price elasticity of demand. Households not covered under the WII would be especially vulnerable due to inflation (poor non-farming population or firms that produce other crops than those that are insured). ${ }^{4}$ This perverse price effect is likely even more important in less developed countries and in WII programs that cover perishable commodities of life stock or vegetables.

\section{Conclusion}

In this paper we outline the rapidly growing Mexican weather index insurance program and discuss some associated challenges. In particular we suggest that the thresholds of the weather index be (continuously) re-calibrated in order to adjust for the development of drought resistant seeds. Secondly, the index could relatively easily be extended to account for precipitation variances. Thirdly we point out potential spill-over effects on 
related markets: WII creates disincentives to invest in other non-insured crops leading to potential overspecialization and monoculture. WII further generates disincentives to invest in irrigation systems because farmers are insured only as long as production takes place on non-irrigated land. Finally, in case of catastrophic events food prices can inflate with indemnity payments at the expense of the uninsured poor. Clearly further research is necessary, in order to evaluate the magnitude and the potential importance of these various side effects of WII. For preliminary results see Fuchs and Wolff (2010).

\section{References:}

Agroasemex. 2006. “La Experiencia Mexicana en el Desarrollo y Operación de Seguros Paramétricos Orientados a la Agricultura.” Working Paper, April 19, 2006. http://www.agroasemex.gob.mx

Alderman, H., and T. Haque. 2008. "Insurance Against Covariate Shocks”, The World Bank: Working paper \#95.

Barnett, B., C. Barrett, C. and J. Skees. 2008. "Poverty Traps and Index-Based Risk Transfer Products.” World Development 36:1766-1785.

Barnett, B. and O. Mahul. 2007. "Weather Index Insurance for Agriculture and Rural Areas in Lower Income Countries." American Journal of Agricultural Economics 89:1241-1247.

Berzsenyi, Z., B. Györffi and D. Lap. 2000. "Effect of crop rotation and fertilisation on maize and wheat yields and yield stability in a long-term experiment.” European Journal of Agronomy 13:225-244. 
Cai, H., Y. Chen, , H. Fang, , and L. Zhoi,. 2009. "Microinsurance, Trust, and Economic Development: Evidence from a Randomized Natural Field Experiment.” NBER Working Paper 15396. http://www.nber.org/papers/w15396. Accessed October 15, 2009.

Cao, M., A. Li, and J. Wei. 2003. "Weather Derivatives: A New Class of Financial Instruments” Social Science Research Network. Working Paper.

Chantarat, S., C. Barrett, A.G. Mude, and T.G. Turvey. 2007. "Using Weather Index Insurance to Improve Drought Response for Famine Prevention.” American Journal of Agricultural Economics 89:1262-1268.

Cole, S., X. Giné, J. Tobacman, P. Topalova, R. Townsend, and J. Vickery. 2009. "Barriers to Household Risk Management: Evidence from India," mimeo.

Fuchs, A. and H. Wolff. 2010. "Drought and Retribution: Evidence from a large scale Rainfall-Indexed Insurance Program in Mexico”, UC-Berkeley working paper.

Giné, X., and D. Yang. 2009. "Insurance, credit, and technology adoption: Field experimental evidence from Malawi.” Journal of Development Economics 89:1-11.

Giné, X., R. Townsend, and J. Vickery. 2007. “Statistical Analysis of Rainfall Insurance Payouts in Southern India”, Working Paper.

Ginocchio, M. 2008. "Weather derivatives becoming hot commodities." USA Today, June 9th, 2008. Available online at:

http://www.usatoday.com/weather/forecast/2008-06-09-weather-derivative_N.htm (accessed June 13, 2010). 
Mahul, O. 2001. “Optimal Insurance Against Climatic Experience.” American Journal of Agricultural Economics 83:593-604.

Ministry of Agriculture. 2009, Evaluación Externa de Resultados, Programa de Atención a Contingencias Climatológicas (PACC), Universidad Autónoma de Chapingo.

Morduch, J. 1995. "Income Smoothing and Consumption Smoothing." Journal of Economic Perspectives 9:103-114.

Osgood, D. and K. Shirley. 2010. "The impact of thresholds on risk behavior: What's wrong with index insurance?” Paper presented at AAEA, CAES \& WAEA joint annual meeting, Denver CO, 25-27 July.

Ribaut, J., J. Betran, P. Monneveux and T. Setter. 2009. "Drought Tolerance in Maize.” In Handbook of Maize: Its Biology. Editors: J. L. Bennetzen and S. C. Hake, pp. 311344. Springer New York.

Rosenzweig, M. R. and H. P. Binswanger. 1993. "Wealth, Weather Risk and the Composition and Profitability of Agricultural Investments.” The Economic Journal 103:56-78.

Sakurai T. and T. Reardon. 1997. "Potential demand for drought insurance in Burkina Faso and its determinants." American Journal of Agricultural Economics 79:11931207.

Skees, J. R. 1999. "Opportunities for improved efficiency in risk sharing using capital markets.” American Journal of Agricultural Economics 81:1228-1233.

Skees, J. R. 2000. “A role for capital markets in natural disasters: A piece of the food security puzzle.” Food Policy 25:365-378. 
Skees, J. R. and E. Ayurzana. 2002. "Examining the feasibility of livestock insurance in Mongolia.” The World Bank, Policy Research Working Paper 2886.

Vedenov, D. and B. Barnett. 2004. “Efficiency of Weather Derivatives as Primary Crop Insurance Instruments.” Journal of Agricultural and Resource Economics 29:387-403. Wolff, H. 2010. "Personal communication with a senior staff member of the Bill and Melinda Gates Foundation.”

\section{Endnotes}

${ }^{1}$ While writing this paper we got aware that Osgood (2010) offers an additional interpretation of the results by Giné and Yang. Farmers who are concerned about income thresholds might be more interested in production increases than risk reduction, and, consistent with the Malawi insurance implementation strategy, may value the insurance more for making credit possible than for risk reduction per se.

${ }^{2}$ In Mexico non-irrigated farming still clearly dominates. In 2008, agricultural production accounted for up to 20.5 million hectares of which 73.6\% depended exclusively on rain. Maize production covered 7.8 million hectares of which more than 6.9 million (90\%) was non-irrigated land (Ministry of Agriculture, 2009).

${ }^{3}$ The announcements are made through the regional offices of the Program for Direct Assistance in Agriculture or through the "Ventanillas Autorizadas" depending on plots location and county.

${ }^{4}$ In less developed African countries the effect of a local price increase may be even larger because a larger portion of the population directly depends on farm-income (and a 
larger percentage of the population would be hence insured) and because the agricultural markets are likely to be even less well integrated compared to the case of Mexico.

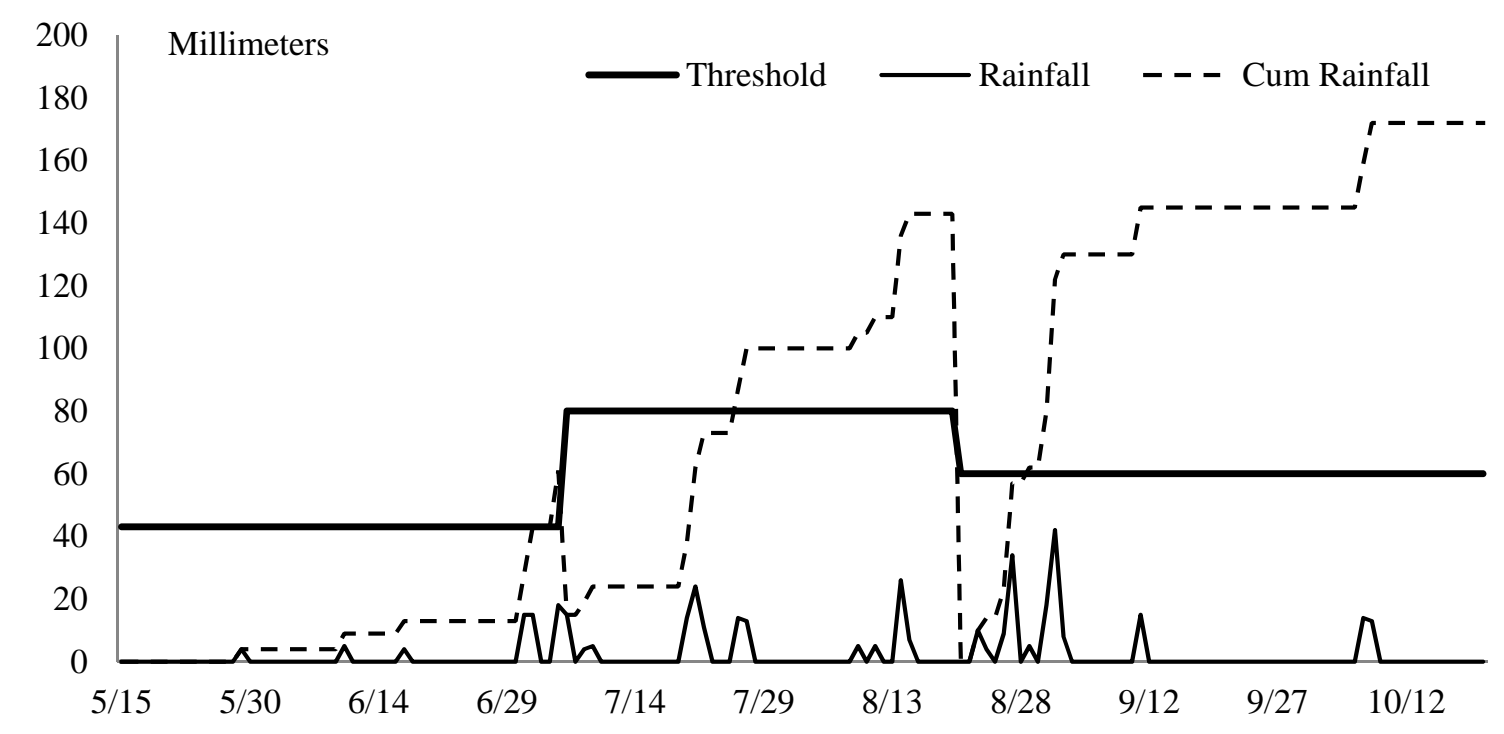

Figure 1: weather insurance thresholds and actual rainfall: Apaseo el Alto, 2005

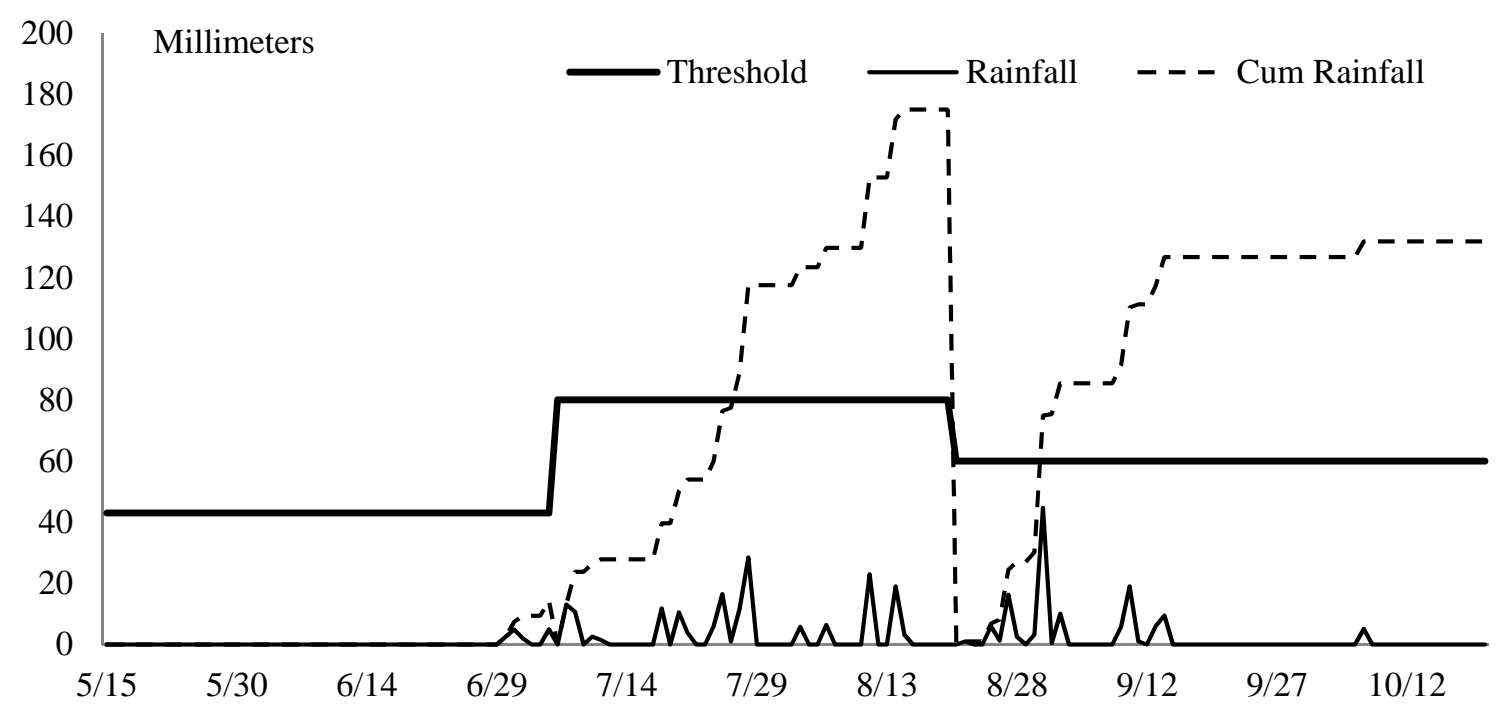

Figure 2: weather insurance thresholds and actual rainfall: Leon, 2005 